\title{
Genç erişkinlerde yeme bağımlılığı ile dürtüsellik arasındaki ilişkinin incelenmesi
}

Atilla TEKİN $^{1}$, Ayşegül YETKİN ${ }^{1}$, Çağla GÜRSOY²

\begin{abstract}
$\ddot{\mathbf{O z}}$
$\mathrm{Bu}$ çalışmanın amacı, genç erişkinlerde, yeme bağımlılığı ile dürtüsellik arasındaki ilişkiyi araştırmaktır. Kesitsel ve tanımlayıcı nitelikteki bu çalışmanın örneklemini, İstanbul ilindeki vakıf üniversitelerinde 2018 yılı itibariyle eğitime devam eden 300 üniversite öğrencisi oluşturdu. Her bir katılımcı, sosyodemografik veri formu ile beraber, Yale Yeme Bağımlılı̆̆ Ölçeği (YYBÖ) ile 30 maddelik Barrat Dürtüsellik Ölçeği'ni (BIS-11) doldurdu. Verilerin istatistiksel analizinde SPSS 22.0 paket programı kullanıldı. Katılımcıların \%21,7'sinde $(\mathrm{n}=65)$ yeme bağımlılı̆̆ saptandı. Yeme bağımlısı olan bireylerin BIS-11 motor dürtüsellik alt ölçek skoru ile BIS-11 toplam skorları, yeme bağımlısı olmayan bireylere göre yüksek saptand1 (sırasiyla, $\mathrm{p}=0,007$ ve $\mathrm{p}=0,029$ ). Regresyon analizi sonucuna göre, BIS- 11 toplam skoru yeme bağımlılığı için bir yordayıcı olarak saptand $($ or=1,04, p=0,030). Yeme bağımlısı bireylerde dürtüsellik bir risk faktörü olarak değerlendirilebilir.
\end{abstract}

Anahtar Kelimeler: Bağımlılık, dikkat, dürtüsellik, genç erişkin, yeme
Yayın Bilgisi

Gönderi Tarihi: 18.04 .2018

Kabul Tarihi:22.06.2018

Online Yayın Tarihi:31.12.2018

DOI: $10.26453 /$ otjhs. 416562

Sorumlu Yazar

Atilla TEKIN

\section{Evaluation of the relationship between food addiction and impulsivity among young adults}

Atilla TEKİN ${ }^{1}$, Ayşegül YETKİN ${ }^{1}$, Çağla GÜRSOY²

\begin{abstract}
The aim of this study was to investigate the relationship between food addiction and impulsivity in individuals young adults. 300 university students who continuing to their education on 2018 were included in this cross-sectional and descriptive study. Each participants fulfilled Yale Food Addiction Scale (YFAS), 30-item Barrat Impulsivity Scale (BIS-11) and a sociodemographic form. The SPSS 22.0 package program was used to statistical analyses of the datas. The prevalance of food addiction was found \%21,7 $(n=65)$ in participants. BIS-11 motor impulsivity subscale and BIS-11 total scores were higher in participants with food addiction than those without food addiction $(p=0,007$ and $p=0,029$, respectively). According to the result of regression analysis, BIS-11 total score was found as a predictor for food addiction (or $=1,04, \mathrm{p}=0,030$ ). Impulsivity may be considered as a risk factor for individuals with food addiction.
\end{abstract}

Article Info

Keywords: Dependence, attention, impulsivity, young adult, food

Corresponding Author

Atilla TEKIN

\footnotetext{
${ }^{1}$ Haliç Üniversitesi, Psikoloji Bölümü, İstanbul

${ }^{2}$ Serbest Klinik Psikolog, İstanbul
}

\section{GíRIŞ}

Son yıllarda farklı bir bağımlılık tipi olarak tanımlanan yeme bağımlılığı, birçok çalışma için önemli bir araştırma konusu haline gelmiştir. Özellikle yüksek kalorili ve glukoz içeriği fazla olan yiyeceklerin, aşerme belirtilerine sebep olduklarının gözlenmesi ile yeme davranışı ve yeme bağımlılığı daha çok araştırılmaya başlanmıştır. ${ }^{1,2}$ Yeme bağımlılığı, yüksek kalorili ve glukozdan zengin "aşırı lezzetli" bazı besinlerin yoğun ve anormal tüketimi olarak tanımlanmıştır. Bazı çalışmalar, yeme bağımlılığı olan bireylerin yeme davranışını kontrol edebilmekte zorluk yaşadıklarını bildirmiştir. $^{3}$ 
Yakın zamanda madde bağımlılığı tanı ölçütlerine göre geliştirilmiş özdeğerlendirme ölçekleri ile yeme bağımlılığı için risk taşıyan bireyler tanımlanmaya başlamıştır. ${ }^{3,4}$ Yeme bağımlılığının madde bağımlılığı tanı ölçütlerine göre tanımlanmasının önemli sebeplerinden birisi, bazı yiyeceklerin santral sinir sisteminde tıpkı psikoaktif maddeler gibi etki göstermesidir. Çikolata gibi bazı yiyeceklerin santral sinir sistemindeki mezolimbik yolakta (ödül yolağı) dopamin salınımını arttırdığı gösterilmiștir. Ayrıca, bağımlılık yapabildiği düşünülen yiyeceklerin insula, orbitofrontal korteks ve singulat korteks gibi madde bağımlılığında da önemli role sahip nöroanatomik bölgelerde aktivasyonu arttırdığı saptanmıştır. ${ }^{5-7}$

Bazı davranışların olumsuz sonuçlarına rağmen davranış üzerindeki kontrolün sağlanamaması, içsel veya dişsal uyarana dair bilgi işlemleme tamamlanmadan eyleme geçilmesi dürtüsellik olarak tanımlanmaktadır. ${ }^{8}$ Birçok çalışmada bağımlılık ile dürtüsellik arasında bir ilişki olduğu gösterilmiştir. Özellikle madde bağımlılarında karar verme mekanizması ile madde kullanımı üzerindeki dürtü inhibisyonunun bozuk olduğu gösterilmiştir. Daha dürtüsel bireylerde, özellikle kompulsif madde kullanımının fazla olduğu bildirilmiştir. ${ }^{9,10}$ Literatürde madde bağımlılığı ile dürtüsellik ilişkisini araştırmış çok sayıda yayın mevcuttur. ${ }^{11,12,13}$ Ancak yeme bağımlılı̆̆ ile dürtüsellik ilişkisi henüz yeterince araştırılmamıştır. $\mathrm{Bu}$ çalışmanın amacı, genç erişkinlerde yeme bağımlılığı ile dürtüsellik arasındaki ilişkiyi araştırmaktır.

\section{MATERYAL ve METOT}

Çalıșmanın örneklemini evreni belli örneklem hesabına göre, $\% 95$ güven aralığı ve $\% 5$ hata payı dikkate alınarak hesaplanmıştır. Buna göre, çalışmanın örneklemini, 2018 yılında İstanbul'daki vakıf üniversitelerinde eğitimine devam eden 300 üniversite öğrencisi oluşturmuştur. Çalışmanın amacı tüm katılımcılarına yazılı olarak bildirildi. Gönüllü her bir katılımcı bilgilendirilmiş onam formunu imzaladı. Çalışmaya ağır ruhsal hastalığı (bipolar bozukluk, şizofreni, alkol veya madde kullanım bozukluğu) olanlar, halen psikotrop ilaç kullananlar dahil edilmedi. Çalışmanın etik kurul onay1, Haliç Üniversitesi Girişimsel Olmayan Klinik Araştırmalar Etik Kurulu'nun 24.04.2017 tarih ve 100 sayılı kararı ile alınmıștır.

\section{Veri Toplama Araçları}

Sosyodemografik Veri Formu: Kat1lımc1ların yaş, cinsiyet, tıbbi hastalık öyküsü gibi kişisel bilgilerini içermektedir.

Yale Yeme Băğmlılı̆̆ Ölçeği: Gearhardt ve arkadaşları tarafından, DSM-IV-TR madde bağımlılığ1 tanı kriterlerini göz önüne alarak geliştirilmiştir. $^{14}$ Bayraktar ve arkadaşları tarafından Türkçe'ye uyarlanmıştır. ${ }^{15}$ Yeme Bağımlılığı Ölçeği için yapılan güvenilirlik analizinde ölçeğin Cronbach's Alfa değeri 0,93 bulunmuştur. Ölçek 27 sorudan oluşmaktadır. 
Yeme bağımlılığı tanısı için 7 tanısal ölçütten en az 3 tanesinin karşılanmasına ek olarak klinik anlamlılığın olması gerekmektedir. Klinik anlamlılık, bireyin yeme davranışının olumsuz sonuçlarını tarif etmesi ve olumsuz sonuçlarına rağmen yeme davranışını denetlemekte yeterince başarılı olamaması olarak tanımlanır.

\section{Barrat Dürtüsellik Ölçeği (BIS-11): 30} maddeden oluşan likert tipi bir ölçektir. ${ }^{16}$ Dikkatle ilişkili dürtüsellik, plan yapamama ile ilişkili dürtüsellik ve motor dürtüsellik olmak üzere 3 alt boyutu vardır. Ölçekten alınacak toplam puanın yüksekliği ne kadar fazla ise uygulayıcının dürtüsellik düzeyi o kadar yüksektir. Katılımcının dikkat puanının yüksekliği kişinin daha dikkatsiz davranışlarda bulunduğunu, motor puanının yüksekliği motor hareketlilikteki artışı, plansızlık puanının yüksekliği yaşamı planlamasındaki istikrarsızlık ve plan yapamamaya işarettir. Güleç ve arkadaşları tarafından Barratt Dürtüsellik Ölçeği11 'in Türkçe geçerlilik ve güvenilirlik çalışması yapılmıştır. ${ }^{17}$

\section{İstatistiksel Analiz}

Verilerin istatistiksel analizinde SPSS 22.0 paket programı kullanıldı. Veriler sayı, yüzde, ortalama ve standart sapma olarak hesapland1. Sürekli değişkenlerin normallik dağılımı Shapiro-Wilk testi ile analiz edildi. Sürekli değişkenler, normal dağılıma uyduğu için verilerin analizinde parametrik testler kullanıldı. Gruplar arasında kategorik değişkenler Chi-
Square testi ile, sürekli değişkenler t-testi kullanılarak karşılaştırıldı. Yeme bağımlılığının olası yordayıcılarını saptamak için ileriye doğru aşamalı regresyon analizi kullanıldı. Elde edilen bulgular \%95 güven aralığında, \%5 anlamlılık düzeyinde değerlendirildi.

\section{BULGULAR}

Katılımcıların yaş ortalaması $21,17 \pm 1,76$ yıl olarak saptandı. Katılımcıların yarısı kadın $(n=150) \quad$ ve yarıs1 erkeklerden $\quad(n=150)$ oluşmuştur. YYBÖ verilerine göre, yeme bağımlılığ Kadın $(\% 22, n=33)$ ve erkek $(\% 21,3, n=32)$ cinsiyetler arasında yeme bağımlılığı oranı açısından istatistiksel fark saptanmadı $(p=0,05)$.

Yeme bağımlılığı olan bireylerin BIS-11 motor dürtüsellik alt ölçek skoru ile BIS-11 total skoru, yeme bağımlılığı olmayan bireylere göre istatistiksel olarak yüksek saptand $1(p=0,07$ ve $\mathrm{p}=0,029)$. Yeme bağımlılı̆̆ olan ve olmayan bireylerde, BIS-11 dikkatle ilişkili dürtüsellik ve plan yapamama ile ilişkili dürtüsellik alt ölçek skorları açısından istatistiksel olarak fark saptanmadi $(\mathrm{p}=0,05$ ve $\mathrm{p}=0,59)($ Tablo 1$)$.

Yeme bağımlılığı yordayıcılarını saptamak amaciyla oluşturulan regresyon modeline cinsiyet (gölge değişken olarak dahil edildi), BIS-11 dikkat ile ilişkili dürtüsellik, BIS-11 motor dürtüsellik, BIS-11 plan yapamama ile ilişskili dürtüsellik ve BIS-11 toplam skorları dahil edildi. Oluşturulan regresyon modelinin, 
yeme bağımlılığı tanısı için toplam etki oranının \%22,9 olduğu saptand1. İleriye doğru aşamalı regresyon analizi sonucuna göre sadece BIS-11 motor dürtüsellik toplam skoru yeme bağımlılığ için bir yordayıcı olarak saptand 1 (or $=1,04$, $\mathrm{p}=0,030)($ Tablo 2).

$\mathrm{Bu}$ çalışmanın en önemli bulguları, genç yetişkinlerin önemli bir kısmında yeme bağımlılığı olması ve yeme bağımlılığı olan bireylerde motor dürtüsellik ve dürtüsellik toplam skorlarının daha yüksek olmasıdır.

Son yıllarda yeme bağımlılı̆̆ yaygınlığını araştıran birçok çalışmanın verileri yayımlanmıştır. Yakın zamanda Türk toplumunda yapılan bir çalışmanın bulgularına göre, üniversite öğrencilerinde yeme bağımlılığı oranı $\% 11,4$ olarak saptanmıştır. ${ }^{18}$ Türk toplumunda yapılmış başka bir çalışmada, yetişkinlerde yeme bağımlılığı oranı \%11 olarak bildirilmiştir. $^{19}$ Başka toplumlarda yapılan çalışmalarda da farklı yeme bağımlılı̆̆ yaygınlığı farklı oranlarda saptanmıştır. Brunault ve arkadaşları, klinik olmayan bir örneklemde yeme bağımlılığı yaygınlığını \%7,2 olarak saptamıştır. ${ }^{20}$ Sağlıklı bireylerin oluşturduğu bir örneklemde yeme bağımlılığı oranının $\% 16,9$ olarak bildirilmiștir. ${ }^{21}$ Amerika'da sağlıklı gönüllülerle yapılan bir çalışmanın bulgularına göre, katılımcıların \%25,7'si yeme bağımlılığı tanı ölçütlerini karşılamaktadır. ${ }^{22}$ Almanya'da üniversite öğrencileri ile yapılan bir araştırmada ise, yeme bağımlılığı yaygınlığı $\% 7,8$ olarak saptanmıştır. ${ }^{23} \mathrm{Bu}$ çalışmanın bulgularına göre ise, üniversite öğrencilerinden oluşan örneklemde yeme bağımlılığ̀ yaygınlığ \%21,7'dir. Literatürden elde edilen verilere göre, yeme bağımlılığı oranı geniş bir yelpazede yaygınlık göstermektedir. Çalışmalarda farklı yaygınlık oranlarının elde edilmesi, çalışmaların kesitsel özellikte olması ve çalışma örneklemlerinin farklı özelliklere sahip olmaları ile açıklanabilir. Ayrıca yeme bağımlılığı tanısının bir özdeğerlendirme ölçeği ile konulması, katılımcıların öznel yanıtları sebebiyle farklı yaygınlık oranlarının elde edilmesine sebep olabilir.

$\mathrm{Bu}$ çalışmanın bulgularına göre, cinsiyetler arasında yeme bağımlılığı yaygınlığı farklılık göstermemiştir. Gearhardt ve arkadaşları, genel popülasyonda yeme bağımlılı̆g yaygınlığının cinsiyetler arasında farklılıklar göstermediğini bildirmiştir. $^{24}$ Amerikan toplumunda yapılmış bir araştırmanın sonuçları da yeme bağımlılı̆̆1 yaygınlığının cinsiyetler arasında fark göstermediğini ortaya koymuştur. ${ }^{25}$ Ancak özellikle kadınlarda yeme bağımlılı̆̆ yaygınlığının daha fazla olduğunu bildiren yayınlar da mevcuttur. Türk toplumunda yapılan bir araştırmanın bulgularına göre, cinsiyetler arasında yeme bağımlılığı yaygınlığı açısından fark saptanmamıştır. ${ }^{18}$ Flint ve arkadaşları, yeme bağımlılığı yaygınlığının kadınlarda daha fazla olduğunu bildirmiştir. ${ }^{26}$ Literatürde cinsiyetler arasında yeme bağımlılığı yaygınlığının farklı 
sonuçlar göstermiş olması, çalışmaların kesitsel özellikte olması ile açıklanabilir.

\section{TARTIŞMA VE SONUÇ}

$\mathrm{Bu}$ çalışmanın önemli bulgularından biri de, yeme bağımlısı bireylerin motor dürtüsellik ve dürtüsellik toplam puanlarının yeme bağımlısı olmayan bireylere göre daha yüksek olmasıdır. Ayrıca bu çalışmada, dürtüsellik toplam skoru yeme bağımlılı̆̆ı için yordayıcı olarak saptanmıştır. Her ne kadar literatürde madde bağımlılığı ile dürtüsellik arasındaki ilişkiyi bildiren çok sayıda çalışma olsa da, yeme bağımlılığı ile dürtüsellik arasındaki ilişkiye dair bilgiler oldukça sınırlıdır. Bariatrik cerrahi adayı bireylerde yapılan bir araştırma, dürtüsellik total skorları ile yeme bağımlılığı arasında ilişki olduğunu göstermiştir. ${ }^{27}$ Meule ve arkadaşları, obez bireylerde dikkatle ilişkili dürtüsellik ve motor dürtüsellik yeme bağımlılığını birlikte yordadığını bildirmiştir. ${ }^{28}$ Mevcut bulgular göZ önünde bulundurulduğunda, dürtüselliğin yeme bağımlılı̆̆ı ile pozitif yönlü bir ilişkisi olduğu söylenebilir.

$\mathrm{Bu}$ çalışmanın birtakım kısıtlılıkları mevcuttur. Araştırmanın kesitsel nitelikte olması, değişkenler arasında kesin olarak bir sebepsonuç ilişkisi olduğunu göstermez. Bir diğer kısıtlılık, yeme bağımlılı̆̆ı başta olmak üzere elde edilen bilgilerin özdeğerlendirme ölçekleri ile elde edilmesidir. Elde edilen bilgiler, katılımcıların öznel bildirimleri ile sınırlıdır.
Gelecekte, klinik değerlendirme esas alınarak yapılacak çalışmalara ihtiyaç vardır.

\section{SONUÇ}

Yeme bağımlılığı, genç erişkinlerin önemli bir kısmında mevcut olabilir. Dürtüselliğin yeme bağımlılı̆̆ı ile bir ilișkisi olduğu söylenebilir. Yeme bağımlısı bireylerin takip ve tedavisinde, çok disiplinli bir yaklaşım daha olumlu sonuçlar elde edilmesine yardımcı olabilir.

\section{KAYNAKLAR}

1. Pelchat ML. Food addiction in humans. J Nutr. 2009;139(3):620-622

2. Avena NM, Gold MS. Food and addictionsugars, fats and hedonic overeating. Addiction. 2011;106(7):12141215

3. Tuomisto T, Hetherington MM, Morris MF, Tuomisto MT, Turjanmaa V, Lappalainen R. Psychological and physiological characteristics of sweet food "addiction". Int J Eat Disord. 1999;25(2):169-175.

4. Gearhardt AN, Corbin WR, Brownell KD. Food addiction: an examination of the diagnostic criteria for dependence. J Addict Med. 2009;3(1):1-7.

5. Blumenthal DM, Gold MS. Neurobiology of food addiction. Curr Opin Clin Nutr Metab Care.2010;13(4):359-365.

6. Gearhardt AN, Yokum S, Orr PT, Stice E, Corbin WR, Brownell KD. Neural correlates 
of food addiction. Arch Gen Psychiatry. 2011;68(8):808-816.

7. Volkow ND, Wang GJ, Fowler JS, et al."Nonhedonic" food motivation in humans involves dopamine in the dorsal striatum and methylphenidate amplifies this effect. Synapse. 2002;44(3):175-180.

8. Moeller FG, Barratt ES, Dougherty DM, Schmitz JM, Swann AC. Psychiatric aspects of impulsivity. Am J Psychiatry. 2001;158(11):1783-1793.

9. Krmpotich T, Mikulich-Gilbertson S, Sakai J, Thompson L, Banich MT, Tanabe J. Impaired decision-making, higher impulsivity, and drug severity in substance dependence and pathological gambling. J Addict Med. 2015;9(4):273-280

10. Crews FT, Boettiger CA. Impulsivity, frontal lobes and risk for addiction. Pharmacol Biochem Behav. 2009;93(3):237-247.

11. Loree AM, Lundahl LH, Ledgerwood DM. Impulsivity as a predictor of treatment outcome in substance use disorders: review and synthesis. Drug Alcohol Rev, 2015;34(2):119-134.

12. Holmes AJ, Hollinshead MO, Roffman JL, Smoller JW, Buckner RL. Individual differences in cognitive control circuit anatomy link sensation seeking, impulsivity, and substance use. J Neurosci. 2016;36(14):4038-4049.

13. Stevens L, Verdejo-García A, Goudriaan AE, Roeyers H, Dom G, Vanderplasschen W.
Impulsivity as a vulnerability factor for poor addiction treatment outcomes: a review of neurocognitive findings among individuals with substance use disorders. J Subst Abuse Treat. 2014;47(1):58-72.

14. Gearhardt AN, Corbin WR, Brownell KD. Preliminary validation of the Yale Food Addiction Scale. Appetite. 2009;52:430-436.

15. Bayraktar F, Erkman F, Kurtuluş E. Adaptation study of Yale food addiction Scale. Klinik Psikofarmakol Bulteni. 2012;22(1):38.

16. Patton JH, Stanford MS, Barratt ES. Factor structure of the Barratt impulsiveness scale. J Clin Psychol.1995;51:768-74.

17. Güleç H, Tamam L, Yazıcı Güleç M, Turhan M, Karakuş G, Stanford MS. Psychometric properties of the Turkish version of the barratt impulsiveness scale-11. Klinik Psikofarmakol Bulteni. 2008;18:251-258.

18. Kıcalı F. 'Üniversite Öğrencilerinde Beslenme Alışkanlıkları Ve Yeme Bağımlılığının Farklı Kişilik Özellikleri Ve Psikiyatrik Belirtilerle İlişkinin İncelenesi’. Tıpta Uzmanlık Tezi, T.C. Selçuk Üniversitesi Tıp Fakültesi. Konya, 2015.

19. Balaman İ. 'Bakırköy İlçesindeki Yetişkin Popülasyonda Yeme Bağımlılığı Ve İlişkili Etmenler'. Yüksek Lisans Tezi, Haliç Üniversitesi Sosyal Bilimler Enstitüsü Psikoloji Anabilim Dalı Klinik Psikoloji Yüksek Lisans Programı. İstanbul, 2017. 
20. Brunault P, Ballon N, Gaillard P, Reveillere C, Courtois R. Validation of the French version of the Yale Food Addiction Scale: An examination of its factor structure, reliability, and construct validity in a nonclinical sample. Can J Psychiatry. 2014;59:276-284.

21. Davis C, Levitan RD, Kaplan AS, Kennedy JL, Carter JC. Food cravings, appetite, and snack-food consumption in response to a psychomotor stimulant drug: The moderating effect of "food-addiction". Front Psychol. 2014;5:1-8.

22. Gearhardt AN, Boswell RG, White MA. The association of "food addiction" with disordered eating and body mass index. Eat Behav2014;15:427-433.

23. Meule A, Kubler A. Food cravings in food addiction: The distinct role of positive reinforcement. Eat Behav. 2012;13:252-255.

24. Gearhardt AN, Boswell RG, White MA. The association of "food addiction" with disordered eating and body mass index. Eat Behav. 2014:15(3);427-433.

25. Eichen DM, Lent MR, Goldbacher E, Foster GD. Exploration of "food addiction" in overweight and obese treatment-seeking adults. Appetite. 2013;67;22-24.

26. Flint AJ, Gearhardt A, Corbin W, Brownell K, Field A, Rimm E. Food addiction scale measurement in two cohorts of middleaged and older women. Am J Clin Nutr.2014;99: $578-586$.

27. Hernandez J, Cervoni C, Hymowitz G. The effects of impulsivity on food addiction and eating behaviors in a bariatric sample. Surg Obes Relat Dis. 2017;13(10):93.

28. Meule A, de Zwaan M, Müller A. Attentional and motor impulsivity interactively predict 'food addiction'in obese individuals. Compr Psychiatry. 2017;72:83-87. 
Tablo 1. Yeme bağımlılığı olan ve olmayan katılımcıların Barrat Dürtüsellik Ölçeği alt ölçek ve total skorlarının karşılaştırılması.

\begin{tabular}{lcccc}
\hline & $\begin{array}{c}\text { Yeme Bağımlısı Olanlar } \\
(\mathbf{n = 6 5})\end{array}$ & $\begin{array}{c}\text { Yeme Bağımlısı } \\
\text { Olmayanlar (n=235) } \\
\text { Ortalama } \pm \text { Standart } \\
\text { Sapma }\end{array}$ & $\begin{array}{c}\text { Ortalama } \pm \text { Standart } \\
\text { Sapma }\end{array}$ & $\mathbf{p}$ \\
\hline $\begin{array}{l}\text { Dikkatle İlişkili } \\
\text { Dürtüsellik }\end{array}$ & $18,923 \pm 3,654$ & $18,038 \pm 3,101$ & $-1,956$ & 0,05 \\
& & & & \\
Motor Dürtüsellik & $24,539 \pm 5,534$ & $22,502 \pm 4,356$ & $-3,135$ & 0,007 \\
Tasarlanmamış & $27,462 \pm 4,514$ & & & \\
Dürtüsellik & & $27,796 \pm 4,379$ & 0,541 & 0,589 \\
Dürtüsellik Genel & $70,923 \pm 10,094$ & & & \\
& & $68,336 \pm 7,926$ & $-2,188$ & 0,029 \\
\hline
\end{tabular}

Tablo-2. Genç yetişkinlerde yeme bağımlılı̆̆ı tanısının yordayıcıları (İleriye doğru aşamalı regresyon analizi ile)

\begin{tabular}{lcccccc}
\hline & B & S.Hata & $\mathbf{p}$ & OR & \multicolumn{2}{c}{$\%$ 95 Güven Aralı̆̆ } \\
& & & & & Alt & Alt \\
\hline Dürtüsellik Genel & 0,035 & 0,016 & 0,030 & 1,036 & 1,003 & 1,069 \\
Sabit & $-5,015$ & 1,293 & 0,000 & 0,007 & & \\
Cox\&Snell $\mathrm{R}^{2}=0,229 ;$ & Nagelkerke $\mathrm{R}^{2}=0,324$ & & & & \\
\end{tabular}

